\title{
Publisher's Note: Experimental evidence of the superfocusing effect for axially channeled MeV protons [Phys. Rev. B 94, 075415 (2016)]
}

M. Motapothula, S. Petrović, N. Nešković, and M. B. H. Breese

(Received 19 August 2016; published 24 August 2016)

DOI: 10.1103/PhysRevB.94.079910

This paper was published online on 11 August 2016 with an Acknowledgment omission. The Acknowledgment should read as "S.P. and N.N. acknowledge the support to this work provided by the Ministry of Education, Science and Technological Development of Serbia through project Physics and Chemistry with Ion Beams, No. III 45006." The Acknowledgment has been added as of 22 August 2016. The Acknowledgment is present in the printed version of the journal. 